Review Article

\title{
Article Review on Vectran-Super Fiber from Thermotropic Crystals of Rigid-Rod Polymer
}

\author{
Derseh Yilie limeneh (iD) and Kelem Tiessasie Yilma \\ Ethiopian Institute of Textile and Fashion Technology, Bahir Dar University, Bahir Dar, Ethiopia \\ Correspondence should be addressed to Derseh Yilie limeneh; derseh2003@gmail.com
}

Received 31 December 2020; Accepted 13 April 2021; Published 26 April 2021

Academic Editor: Roberto Brighenti

Copyright (c) 2021 Derseh Yilie limeneh and Kelem Tiessasie Yilma. This is an open access article distributed under the Creative Commons Attribution License, which permits unrestricted use, distribution, and reproduction in any medium, provided the original work is properly cited.

\begin{abstract}
According to the economic and environmental perspective, multifilament Vectran, yarn spun from liquid crystal polymer, is important because of its quite simple processing during spinning in a wide range of injection moulding, extrusion moulding, and melt spinning. Vectran fiber is an aromatic polyester spun from a liquid crystal polymer in a melt extrusion process. This process orients the molecules along the fiber axis, resulting in a high tenacity fiber, and Vectran melts at $330^{\circ} \mathrm{C}$. Heat treatment can improve and vary the tensile strength of Vectran fiber. On average, tensile strength for Vectran is 26 grams/denier (grouped as a high tenacity grade) and the strength of the fiber is maintained after several flexing and bending actions. Abrasion resistance of Vectran is even higher than a similarly sized aramid yarn. In addition, the original dimensions are maintained under variance of temperature with negligible creep and shrinkage. Vectran fiber, characterized by its golden color, high strength and modulus, thermal stability at high temperatures, low creep, and good chemical stability, can be used in many various industries starting from ropes and cables to profound sea survey and military products.
\end{abstract}

\section{Introduction}

Liquid crystal polymer is a thermoplastic polymer from aligned molecule chains with spatial regularity of rigid crystal [1]. Affording to the situations in which the liquid crystal is formed, liquid crystal polymer can be parted as thermotropic and lyotropic [2]. The first is by dissolving the polymer with a given solvent to achieve lyotropic liquid-crystal polymers [3, 4], while the second is a thermotropic liquid crystalline polymer, when the liquid crystalline nature is possessing a thermal change under cooling and heating at a given temperature range is due to the chemical nature of polymer $[5,6]$.

Vectran is the second generation of man-made super fibres next to Kevlar and Twaron super fibres as a flexible and rigid polymer and called high-modulus, high tenacity (HM-HT) fibres with a high chemical as well as a thermal struggle [7]. Vectran as HM-HT fiber possesses strength and modulus at least $2 \mathrm{GPa}$ and $50 \mathrm{GPa}$, respectively [8]. Vectran fibres, produced in 1990 for the first time, have been utilized by NASA as airbag landings on Mars Pathfinder and as a layer of spacesuits.
Vectran which is fully aromatic polyester is commercially produced in the melt spinning method and it is the only thermotropic liquid crystalline polymer used on a commercial scale according to [9]. Liquid crystal is due to some molecular motion matching with liquid and ordered crystal $[10,11]$.

Vectran forms a liquid crystal; because of an interactive and rigid polymer, it can easily be oriented through a fiber manufacturing process [12]. Vectran fiber is obtained from the dried and then melted pellet thermotropic liquid crystalline polymer by melt spinning process and when it passes through a spinning hole it gives a high molecular orientation although; the structure of the fiber is achieved under controlled cooling and or solidifications (Figure 1(a)). A great molecular orientation achieved during spinning causes an unnecessary post drawing process [13]. As-spun thermotropic aromatic polyester fibres are not drawable but the properties of the fibres can be enhanced by heat treatment (Table 1). Production of Vectran is called cost-effective since it is a melt-spun fiber than other high-performance fibres like aramids and UHMWPE; however, the requirement of 

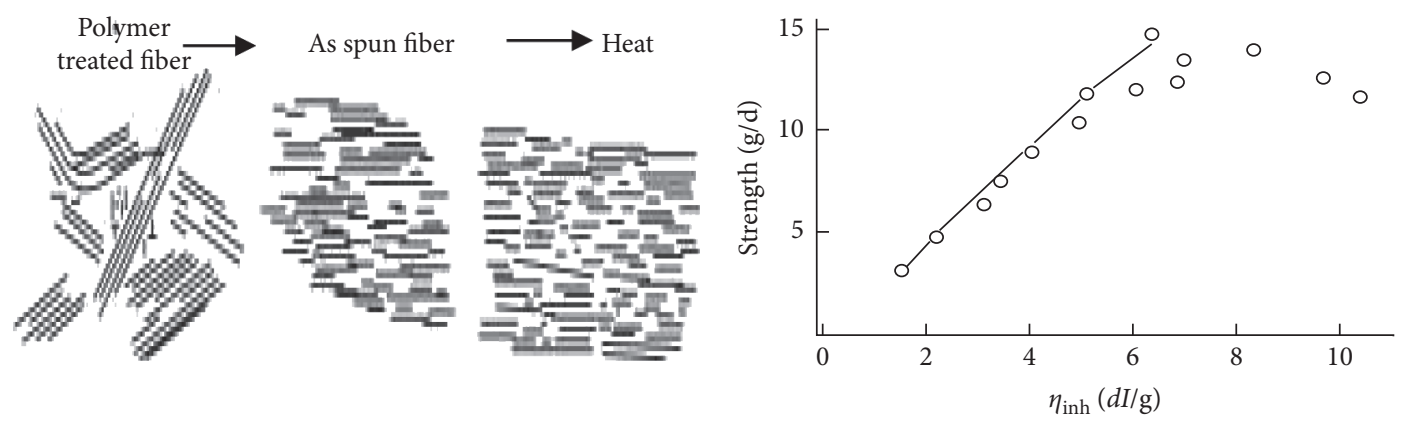

(a)

(b)

Figure 1: (a) Fiber formation of thermotropic liquid crystals; (b) inherent viscosity versus spun fiber strength [19].

TABle 1: A combination of liquid crystal polymer and respective fiber property $[16,23]$.

\begin{tabular}{|c|c|c|c|c|c|c|}
\hline \multirow[b]{2}{*}{ Polymer composition } & \multirow[b]{2}{*}{ Ratio (mol\%) } & \multirow[b]{2}{*}{$\eta_{\text {inh }}$} & \multicolumn{2}{|c|}{ As spun fiber } & \multicolumn{2}{|c|}{ Heat-treated fiber } \\
\hline & & & Tenacity (cN/dtex) & Initial modulus (cN/dtex) & Tenacity (cN/dtex) & $\begin{array}{l}\text { Initial modulus } \\
(\mathrm{cN} / \mathrm{dtex})\end{array}$ \\
\hline HBA/HNA & $75 / 25$ & 5.7 & 10.7 & 477 & 17.7 & 485 \\
\hline $\mathrm{HBA} / \mathrm{HNA}$ & $73 / 27$ & - & - & - & 26.3 & - \\
\hline HBA/HNA/TA/BP & $60 / 5 / 17.5 / 17.5$ & 6.5 & 7.0 & 560 & 24.5 & 980 \\
\hline
\end{tabular}

high heat treatment for solid-state polymerization after melt-spun can offset its economical approaches [13]. The outstanding strength and stability of the aromatic Vectran fiber make it being used in a high-performance purpose including aerospace, military, and industrial applications [14]. This review will map out compressively looking on the possible structure, property, and application of Vectran fiber.

\section{Fiber Spinning Chemistry}

From liquid-crystal phases in mesophases during the processing of LCPs can give injected material and fibres and the macromolecular orientation in the mesophase consequence of the self-reinforcing and high mechanical properties [7]. Because of having oriented and strong vectran fiber means, it is formed from oriented and rigid polymers [15]. Vectran is obtained by acetylation polymerization of p-hydroxybenzoic acid (HBA) and 6-hydroxy2-naphthoic acid (HNA) Figure 2(a). Different composition of the polymer could be used for Vectran productions (Table 1). When the vectran fiber is formed from $75 \%$ of HBA and $25 \%$ of HNA with viscosity and melting point of $5.7 \mathrm{dl} / \mathrm{g}$ and $302^{\circ} \mathrm{C}$, respectively, which gives strength of $12.1 \mathrm{~g} / \mathrm{d}$, elongation of $2.5 \%$, and $541 \mathrm{~g} / \mathrm{d}$ of modulus [16]. This monomer combination could give better molecular weight and make fiber spin at a higher melting point and even above the melting point. Once the fiber formation is completed, there is no post-drawing process so to work on the finer diener there needs to be a narrow spinneret hole and or increasing spin draw or attenuations.

Having narraw spinnerate hole during the production of vectran fiber has the ability to increase the shear rate and reduce the viscosity of melting $\left(\eta_{\mathrm{inh}}\right)$. This is because thermotropic liquid crystal polymers possess a linear letdown of viscosity as shear rate increases (even in low shear rate region). The attenuation and spinnerate hole can influence the orientation and the structure. The die swells effect also is small here since rapid solidifications occur even at a combination of HBA and HNA:75/25 show a negligible die swell as a function of shear stress [7]. Until the viscosity is optimum, the strength is better; however, if is beyond $7 \mathrm{dl} / \mathrm{g}$, the strength will be declined Figure 1(b).

The outstanding strength of the Vectran is due to the solid-state polymerizations at $240^{\circ} \mathrm{C}-320^{\circ} \mathrm{C}$ but not more than melting temperature to prevent filament sticking after melt spinning process) and tenacity of $23-28 \mathrm{~g} / \mathrm{de}-$ nier tenacity is achieved (Table 1). However, the modulus increases only slightly, the crystallinity increases to $20 \%$, and molecular weight increases by three times [9]. This is due to an increasing in the chain length, molecular weight, and crystallinity with a long-time heat treatment once the fiber is in the solid state [12,17]. Solid-state polymerization occurs in a normal pressure atmosphere or a reduced pressure [18]. There is an increment of the number average molecular weight and weight average molecular weight of as-spun fiber from 1.63 to 4.89 and 3.84 to 14.5 correspondingly $[19,20]$. Heat treatment of the fiber is not only for the improvement of fiber strength and modulus but also the thermal nature of the fiber [21]. As heat treatment is increased, the strength has to be improved $[22,23]$.

2.1. Molecular Chain Structure. A class of polymeric constituents measured by rigid-rod linear molecules that are highly anisotropic is called liquid crystalline polymers 


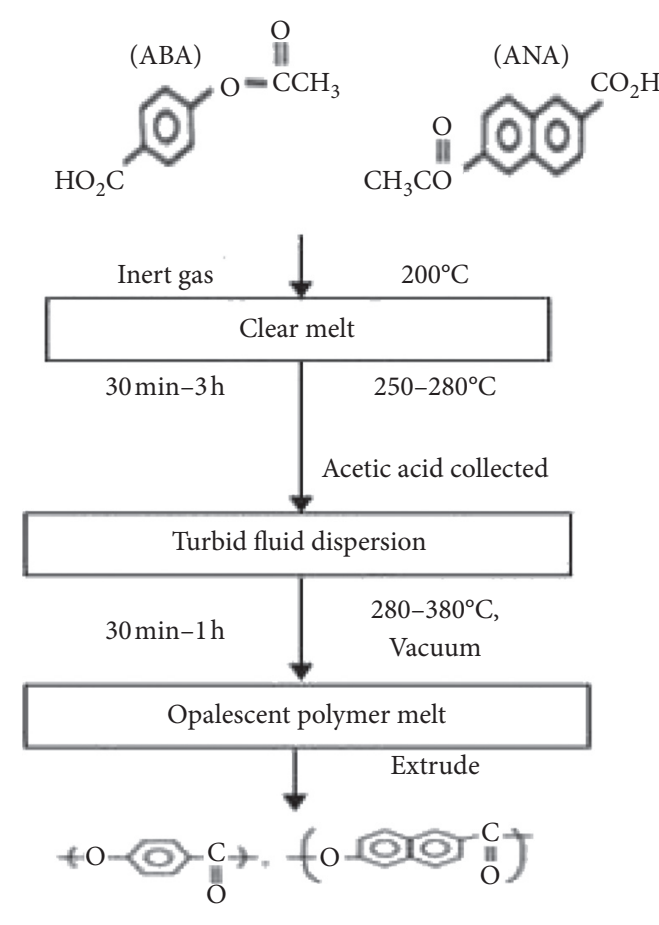

(a)

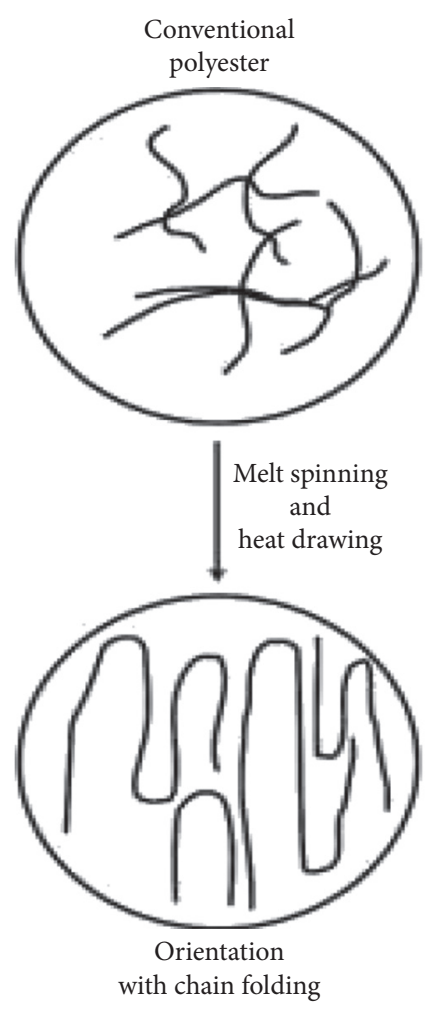

(b)

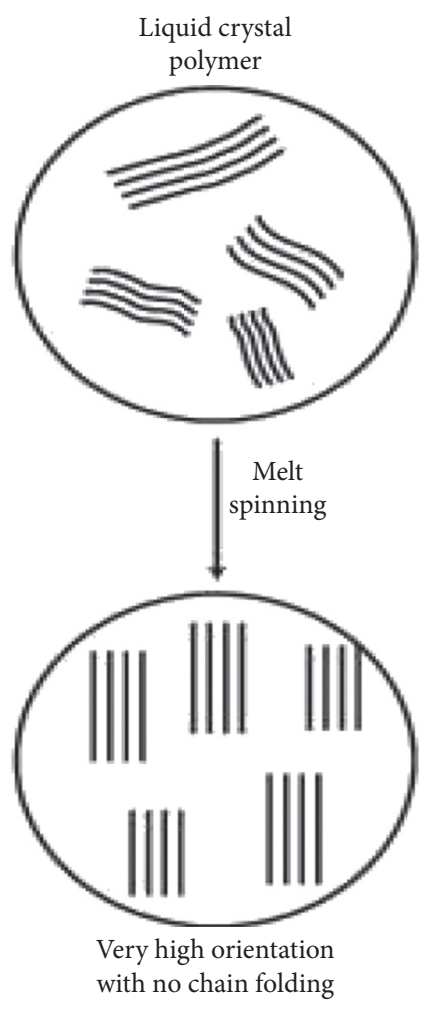

)

Figure 2: (a) Polymerization process for HBA/HNA copolymer; (b) molecular orientation in conventional and liquid crystal polymer [29].

(LCPs). The inherent molecular anisotropy and having a long relaxation time during the processing of a thermotropic liquid crystal polymer (TLCP) can cause orientation and morphology of parts and it is highly reliant on the process conditions [24]. The molecular structure of a liquid crystal polymer as the main chain and side chain is due to the location of the liquid crystal $[25,26]$. The molecules of the liquid crystal polymer are rigid and position themselves into randomly oriented domains. The rigid-rode structure of the thermotropic liquid crystal polymer is characterized by its anisotropic nature in the melt state, thus the term "liquid crystal polymer" [27, 28]. The presence of rigid-rodlike molecules results in the self-reinforcing nature of TLCP then finally forms a fibrous structure with great stiffens and strength. The molecules are assembled by themselves even when a thermal change happens on the polymer [29]. Upon the extrusion of the molten polymer through small spinneret holes, the molecular domains align parallel to each other along the fiber axis [30]. This is due to a melt nature of a polymer that leads to orienting the molecule in the fiber axis for high tensile and thermal properties (Figure $2(\mathrm{~b})$ ).

\section{Properties}

Vectran fiber is a super high-performance fibre that is meltspun from liquid crystal polymer in comparison of outstanding mechanical properties at high temperatures, excellent chemical resistance, inherent flame retardancy, high stiffens, very low creep mean that will not stretch with time, good weather ability, and good thermal resistance [7]. The strength and inflexibility of Vectran fiber are five and ten times stronger than steel and aluminium and can possess excellent strength and inflexibility [31]. For an application that requires thread fiber and yarn in the toughest and strongest environmental challenges, Vectran-super fiber from thermotropic crystals of the rigid-rod polymer could be used to satisfy the need.

3.1. Strength of Vectran Fiber. The strength-to-weight ratios of Vectran fiber are higher than traditional metals. Vectran is determined by its high tensile strength in compression of other high-performance fibres including PET, nylon, and aramid and even incomparable with UHMWPE (Table 2). Vectran and industrial fiber are due to their sufficient strength of unique liquid crystal nature sealing in the molecular structure during melt spinning of the fiber [7].

3.1.1. Thermal Property of Vectran Fiber. The melting point of Vectran is around $320^{\circ} \mathrm{C}$ and shows a significant strength loss at $220^{\circ} \mathrm{C}$. The great heat resistance of the Vectran fiber creates a high LOI, low-smoke generation and also a low thermal shrinkage in hot air, boiling water, and laundry process [29]. For the Mars Pathfinder task in 1997, Vectran can be tested at low temperature $\left(-62^{\circ} \mathrm{C}\right)$ and show outstanding tenacity compared to aramid fiber and can be carefully chosen as airbag fabric and external assembly [7]. 
TABle 2: Property of different industrial fibres adopted from [9].

\begin{tabular}{lcccccc}
\hline Materials & $\begin{array}{c}\text { Materials density } \\
\left(\mathrm{g} / \mathrm{cm}^{3}\right)\end{array}$ & $\begin{array}{c}\text { Tensile } \\
\text { strength }(\mathrm{GPa})\end{array}$ & $\begin{array}{c}\text { Tensile } \\
\text { modulus }(\mathrm{GPa})\end{array}$ & $\begin{array}{c}\text { Elongation } \\
\text { at break (\%) }\end{array}$ & $\begin{array}{c}\text { Moisture } \\
\text { regain (\%) }\end{array}$ & Rupture work (mN/tex) \\
\hline Vectran & 1.40 & 3.4 & 70 & 4 & $<0.1$ & 40 \\
PET & 1.38 & 1.1 & 14 & 15 & $<0.5$ & 50 \\
Nylon & 1.14 & 1.0 & 10 & 20 & $6-8$ & 80 \\
Aramid & 1.44 & 3.0 & 65 & 4 & $4-6$ & 35 \\
UHMWPE & 0.95 & 3.4 & 110 & 4 & $<0.1$ & - \\
\hline
\end{tabular}

Vectran has a good thermal protective performance, which is due to a material's ability to safeguard the wearer from second-degree skin burn. As compared to high-temperature resistance of glass, the vectran fiber has better stability property even at high temperature (Table 3). Even after thermal exposure of the Vectran, there is a retention of mechanical property and other properties. Figure 3 shows a relative strength of the Vectran and aramids at different temperature exposure and Vectran shows better strength retention than aramid fiber [9].

3.1.2. Creep Nature. Fiber for long-term static loading creep's nature of the material is important in various applications [9]. Vectran comprises a small creep rate than other high-performance fiber like aramids. The fiber also exhibits no measurable creep when loaded up to $50 \%$ of the thread line breaking load [7]. To produce any material for a specific-end application, the design and the parameter have to be considered [32]. At a fixed elongation in a load cell for a pretention of the rope and because of stress relaxation, the load is decreased over time [31]. As the tension reaches below a predetermined level, there is a re-tensioning and the frequency of re-tensioning is a measure of creep performance of the Vectran fiber rope as can be seen in Figure 4.

3.2. Electrical Property. Vectran possesses excellent electrical property including dielectric, heat resistance, thermal resistance, or stability and can be used for medical devices/ actuators and electronic circuit boards applications [8]. The dielectric property of Vectran fiber is about 3.3 at a frequency of $1000 \mathrm{HZ}$ and because of the non-absorbent of moisture, it can have excellent electrical insulation property [33].

3.3. Other Properties. Vectran is characterized by its minimum stretchability, UV resistance, and abrasion resistance. For the long-term uses in the outdoor environment, it cannot be used without protective coatings since it can possess a low resistance to UV degradation. Mostly the polyester and polyurethane coating is often used to improve abrasion resistance and moisture inertance through a material [34]. Table 4. The abrasion property of Vectran fiber is 10 times better in the case of wet yarn abrasion property than other high-performance fibers including aramid yarns and 39.789 and 3.922 cyclic for a failure at $1 \%$ yarn breaking load which is needed for a Vectran yarn and aramid, respectively, for rope production. The chemical compatibility or stability of Vectran fiber for acid and alkali is less than $90 \%$ and $30 \%$ concentration, respectively [35]. The bending and flexing resistance of Vectran is importantly good. The liquid crystal polymer of Vectran is characterized by its excellent oxygen or water vapour barrier properties than other alternative meltprocessible polymeric material used for barrier application. The level of humidity of air does not give a significant effect on the permeation of numerous gases through Vectra. The greater extent launder-ability of Vectran makes it an excellent choice in cut-resistant applications in comparison with other competitive high-performance materials [31].

\section{Applications}

Vectran fiber is found in about 50 market shares, including for most important applications such as cut-resistant gloves and clothing, sailcloth, fishing line, tow cables, inflatable structures, NASA space systems, heavy-lifting lines, puncture-resistant bicycle tires, and cordage for a medical, aerospace, and sports applications.

4.1. Composite. Thermotropic liquid crystal polymers is called "self-reinforcing thermoplastics" because of its orientation and rheological behaviours advance during processing are very similar to a short fibre-filled composite [36]. The fiber is highly applicable as a reinforcement of material like ropes, cables, protective apparel, advanced composite materials, high-pressure inflatables, and shipping container (Figure 4). The world can also be inspired by Vectran in the recreation industry, as it can be used for reinforced boat hulls, golf clubs, fishing rods and lines bicycle forks, tennis rackets, skis, and snowboards [33].

4.1.1. Flexible Composite. Vectran of aromatic polyester is used as a current and less practised material for composite applications [37]. A flexible composite made with Vectran fiber is due to its ability to experience low radius bending under a repeated bending cycle by protecting the fiber strength than a comparatively high-performance liquid crystal polymer para-aramids [31]. Folded coated fabric made from vectran is applied for the utilization on industrial and military (Figure 5).

4.1.2. Rigid Composite. A rigid composite made with Vectran can be used in many rigid composites even if it can possess a low compressive strength than carbon and glass; this can retard the use of Vectran as reinforcement material aramids [31]. Hybrid construction with carbon and glass is done for vibration damping because a better tensile and 
TABLe 3: Thermal nature of aramid and Vectran high-performance fiber [9].

\begin{tabular}{lcccc}
\hline Material & LOI & Melting temperature $\left({ }^{\circ} \mathrm{C}\right)$ & TGA $(20 \%$ weight loss $)\left({ }^{\circ} \mathrm{C}\right)$ & Heat shrinkage at $180^{\circ} \mathrm{C}$ for 30 min $(\%)$ \\
\hline Vectran & 28 & 320 & $>450$ & $<0.2$ \\
Aramid & 30 & None & $>450$ & $<0.2$ \\
\hline
\end{tabular}

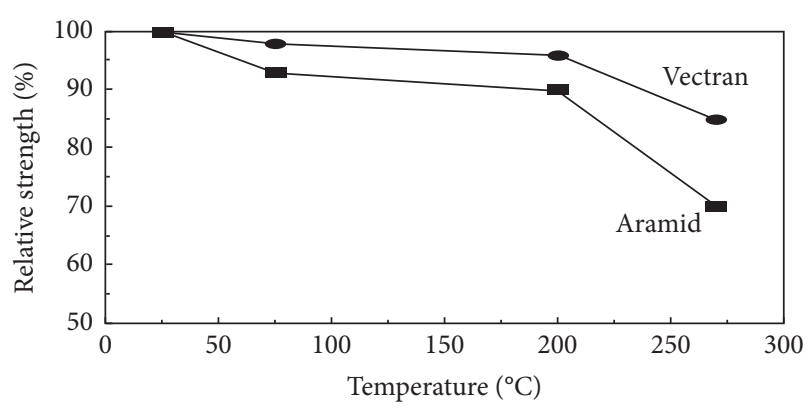

Figure 3: Relative strength in four-day thermal exposure of Vectran and aramid/fiber [9].

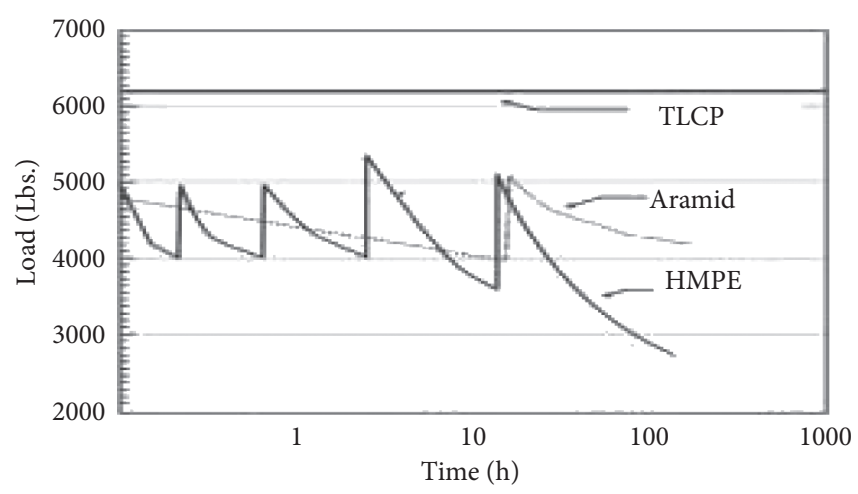

FIGURE 4: Creep experiment was done for Vectran fiber ropes [31].

TABLE 4: Cyclic failure during wet yarn to yarn abrasion test and cut resistance of different fiber [12].

\begin{tabular}{lccc}
\hline \multicolumn{1}{c}{ 1\% of yarn break load } & \multicolumn{2}{c}{ Cut resistance } \\
Materials & $\begin{array}{l}\text { Mean } \\
\text { cyclic }\end{array}$ & $\begin{array}{c}\text { Material/1500 } \\
\text { denier }\end{array}$ & Relative load \\
\hline Aramid & 4097 & Vectran & 3.4 \\
$\begin{array}{l}\text { Kevlar 29 (960) } \\
\text { Twaron 1020 }\end{array}$ & 3922 & Aramid & 1.1 \\
$\begin{array}{l}\text { Vectran } \\
\text { Polyester }\end{array}$ & 39789 & & 1.0 \\
$\begin{array}{l}\text { Diolen 855TN } \\
\text { Trevira 785 }\end{array}$ & 170473 & UHMWPE & \\
\hline
\end{tabular}

compression strength is achieved. The composites made with this fiber have been used for aircraft construction because of low moisture content [9].

4.2. Ropes and Cable Production. The strength, stiffness, and low moisture absorption of Vectran fibres create more efficient and longer-lasting ropes to satisfy market demands for smaller and lighter ropes and cords Figure 6. Product strength is improved in creep and flex fatigue for vectran fiber $[8,35]$. Vectran is a high modulus and tenacity fiber used for the production of industrial ropes. Unless for antenna stays application, the Vectran fiber used for an electrical application has little importance on the rope performances. Low UV resistance of this fiber needs a UV stabilizing additive during fiber production [7]. Apart from a fire, the thermal property of Vectran fiber is not that much important and it possesses excellent microbial and organic solvent resistance, fair sunlight resistance, and good acid and alkali resistance (not if strong chemicals used).

The frictional property of the Vectran fiber is important and a yarn-to-yarn coefficient of friction is about 0.151 which is good for easiness of rope handling and running over other surfaces [12]. In comparison with aramids, Vectran has a good abrasion resistance for good performance of ropes. Vectran from liquid crystal polymer is considered as a strong and stiff fiber and can easily produce wire with minimal width and heaviness and for the production of pipe under high pressure. Besides, to keep the optimal signal quality by protecting the optical cable system from resizing, only minimal creep of Vectran fibres is required $[37,38]$.

4.3. Aerospace. In July 4, 1997, Mars Pathfinder made its notable landing on the surface of Mars, using airbags of Vectran fiber. Because of having high strength and light weight, the vectran fiber has to be used for aerospace application [39]. In addition to strong mechanical performance, negligible off-and out-gassing features of the Vectran fiber are required for high vacuum and space applications [7].

4.4. Fabric and Protective Materials. The fabric from Vectran is characterized by its tear strength, dimensional stability to preserve complex shapes, flex or fold fatigue resistance for frequent placements, pack and unpack rounds, and chemical resistance to survive washing processes [39]. The tensile strength, abrasion, and cut resistance of Vectran fibres advance its uses like protective textiles than traditional fibres and make a protective glove material [40-42]. When the fabric passes through some process like scouring, coating, and seaming, the admirable thermal resistance of the Vectran plays a great role. Dimensional stability and chemical and bleach resistance are important in defensive apparel use and simplify garment care. Owing to this, it can be applicable for defensive textiles, sailcloth, flexible composites, inflatable structures, and motorbike dress [32]. 

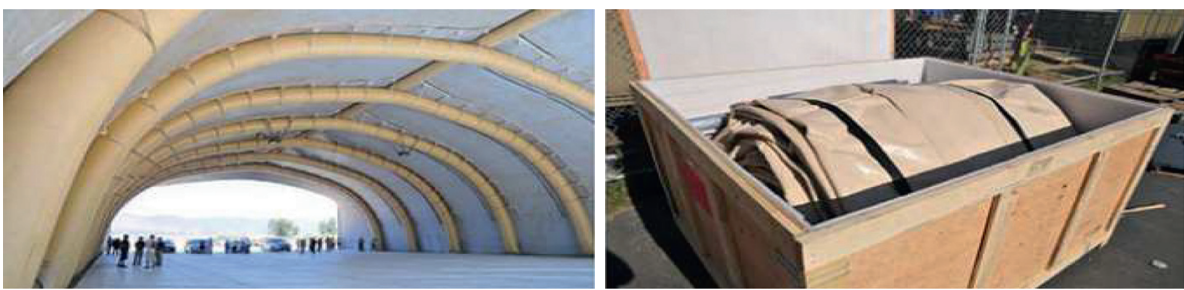

FIGURE 5: Flexible composite pressurized air beams and shipping container [19].
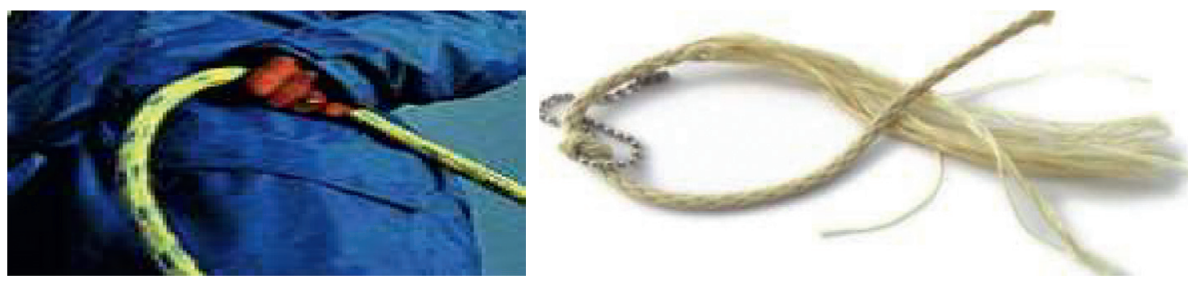

FIgURE 6: Vectran cable and rope (Hearle).

4.5. Nonwoven and Specialty Paper. Because of the low moisture absorption and excellent dielectric property of Vectran fibers, they are used in specialty insulating papers for motors and printed circuit boards [32]. Paper and Nonwoven had a property of high insulating property [39].

4.6. Sport. Sporting goods like paragliders, bike tires, sailcloth, and snowboards can be produced from a dyed Vectran fiber. Vectran is an imaginer fiber for sport good than carbon, glass, and aramid because of its excellent vibration damping performance [29]. Vectran in continental bicycle tires is used as a puncture safety layer [7]. Vectran is used in the non-downgrade performance by decreasing rolling resistance. Now, the reinforcement of the Vectran can have a great performance of bicycle forks [33].

4.7. Medical. Vectran fiber tensile properties make it an excellent choice for catheter reinforcement applications, device delivery systems, and surgical control cables [39]. The gamma sterilization, low or no creep, abrasion resistance, and dimensional stability of this high-performance fiber can also facilitate a more consistent user feel in many medical device applications where tactile feedback is critical [7]. Vectran can be utilized even for the application of veterinary implants for better health condition.

\section{Conclusion}

High strength and modulus super spun fibers called Vectran fibers are because of a rigid-rod structure and being highly symmetric. Vectran spun from a thermotropic liquid-crystal polymer is a man-made fiber by Celanese Corporation. Chemically, the aromatic polyester is due to self-condensation of polyester using 4-hydroxybenzoic acid and 6-hydroxynaphthalene-2-carboxylic acid. The qualities of the Vectra polymer include excellent chemical resistance, property preservation in a varied range of temperatures, excellent mechanical properties, and low moisture pick-up. If a proper finish is given to the Vectran, the excellent abrasion resistance is achieved and mostly it can be applicable for industrial ropes and cables, textiles, sport, medical actuators, composites, aerospace, and electronic circuit boards.
Abbreviations
GPa: Giga pascal
\%: $\quad$ Percentage
${ }^{\circ} \mathrm{C}$ : $\quad$ Degree centigrade
$\mathrm{g} / \mathrm{cm}^{3}$ : Gram per cubic centimetre
dl/g: Deciliters per gram
HZ: Herzen
g/d: $\quad$ Grams per denier
cN/dtex: Centinewton per decitex
h: Hours.

\section{Conflicts of Interest}

The authors declare that there are no conflicts of interest.

\section{References}

[1] X. Wang, J. Engel, and C. Liu, "Liquid crystal polymer (LCP) for MEMS: processes and applications," Journal of Micromechanics and Microengineering, vol. 13, no. 5, pp. 628-633, 2003.

[2] Y. Ji, Y. Bai, X. Liu, and K. Jia, "Progress of Liquid Crystal Polyester (LCP) for 5G Application," Advanced Industrial and Engineering Polymer Research, vol. 3, 2020.

[3] A. Blumstein, Liquid Crystalline Order in Polymers, Elsevier, Amsterdam, Netherlands, 2012.

[4] K. Shaker and Y. Nawab, "Fibers for protective textiles," in Fibers for Technical Textiles, Springer, Cham, Switzerland, 2020.

[5] A. Greiner and H.-W. Schmidt, "Aromatic main-chain liquidcrystalline polymers," Handbook of Liquid Crystals, Wiley, Hoboken, NJ, USA, pp. 1-28, 2014. 
[6] S. Okamoto, M. Hirakawa, and Sumitomo Chemical Co Ltd, "Method for producing a liquid crystalline polyester and the liquid crystalline polyester," U.S. Patent 7.009.026, 2006.

[7] H. Avci, A. Hassanin, T. Hamouda, and A. Kiliç, "High performance fibers: a review on current state of art and future challenges," Eskişehir Osmangazi Üniversitesi Mühendislik Ve Mimarlık Fakültesi Dergisi, vol. 27, no. 2, pp. 130-155, 2019.

[8] K. Hori, Y. Hoshino, and H. Shimizu, Vectran: Development of High-Functionality Fiber and its Applications at Kuraray Co., $L t d$, Institute of Innovation Research, Hitotsubashi University, Tokyo, Japan, 2014.

[9] H. Hoshiro, R. Endo, and F. E. Sloan, "Vectran: super fiber from the thermotropic crystals of rigid-rod polymer," in HighPerformance and Specialty Fibers, pp. 171-190, Springer, Tokyo, Japan, 2016.

[10] S. Okamoto, M. Hirakawa, and Sumitomo Chemical Co Ltd, "Liquid crystalline polyester and method for producing the same," U.S. Patent 6,512,079, 2003.

[11] L. L. Chapoy, Recent Advances in Liquid Crystalline Polymers, Springer Science \& Business Media, Berlin, Germany, 2012.

[12] H. A. McKenna, J. W. Hearle, and N. O'Hear, Handbook of Fibre Rope Technology, Elsevier, Amsterdam, Netherlands, 2004.

[13] R. R. Luise, "Advances in heat-strengthened thermotropic liquid crystalline polymer materials," Applications of High Temperature Polymers, p. 25, CRC Press, Boca Raton, FL, USA, 1997.

[14] W. W. Wright, High Performance Polymers: their Origin and Development, R. B. Seymour and G. S. Kirshenbaum, Eds., Elsevier Science Publishing Co. Inc., New York, NY, USA, 1987.

[15] H. Han and P. K. Bhowmik, "Wholly aromatic liquid-crystalline polyesters," Progress in Polymer Science, vol. 22, no. 7, pp. 1431-1502, 1997.

[16] S. Eichhorn, J. W. S. Hearle, M. Jaffe, and T. Kikutani, "Fundamentals and manufactured polymer fibres," Handbook of Textile Fibre Structure, Elsevier, Amsterdam, Netherlands, 2009.

[17] A. E. Zachariades and R. S. Porter, High Modulus Polymers: Approaches to Design and Development, CRC Press, Boca Raton, FL, USA, 2020.

[18] S. Matsubara, H. Umetsu, T. Hase, and Toray Industries Inc, "Liquid crystalline polyester composition, method of producing the same and molded product manufactured from the same," U.S. Patent 8.778.222, 2014

[19] J. Nakagawa, "Spinning of thermotropic liquid-crystal polymers," Advanced Fiber Spinning Technology, Woodhead Publishing, Cambridge, United Kingdom, pp. 160-171, 1994.

[20] J. Sarlin and P. TörmäLä, "Heat treatment studies of a TLCP fiber," Journal of Applied Polymer Science, vol. 50, no. 7, pp. 1225-1231, 1993.

[21] Y. Yamamoto and J. Nakagawa, "The structure and properties of high-modulus, high-tenacity Vectran fibres," in Handbook of Textile Fibre Structure, pp. 413-428, Woodhead Publishing, Cambridge, United Kingdom, 2009.

[22] J. D. Menczel, G. L. Collins, and S. K. Saw, "Thermal analysis of Vectran fibers and films," Journal of Thermal Analysis, vol. 49, no. 1, pp. 201-208, 1997.

[23] J. E. Taylor, A. Romo-Uribe, and M. R. Libera, "Molecular orientation gradients in thermotropic liquid crystalline fiber," Polymers for Advanced Technologies, vol. 14, no. 9, pp. 595600, 2003.

[24] P. N. Prasad, Frontiers of Polymers and Advanced Materials, Springer Science \& Business Media, Berlin, Germany, 2012.
[25] M. R. Hammond and R. Mezzenga, "Supramolecular routes towards liquid crystalline side-chain polymers," Soft Matter, vol. 4, no. 5, pp. 952-961, 2008.

[26] A. A. Collyer, Liquid Crystal Polymers: from Structures to Applications, vol. 1, Springer Science \& Business Media, Berlin, Germany, 2012.

[27] R. A. Weiss and C. K. Ober, Liquid-crystalline Polymers, American Chemical Society, Washington D.C, WA, USA, 1990.

[28] L. Zhu and C. Y. Li, Liquid Crystalline Polymers, Springer, Berlin, Germany, 2020.

[29] G. Bhat, "Introduction to high-performance fibers," in Structure and Properties of High-Performance Fibers, pp. 1-4, Woodhead Publishing, Cambridge, United Kingdom, 2017.

[30] S. K. Garg and S. Kenig, "Development of orientation during processing of liquid crystalline polymers," High Modulus Polymers: Approaches to Design and Development, p. 71, CRC Press, Boca Raton, FL, USA, 2020.

[31] F. Sloan, "Liquid crystal aromatic polyester-arylate (LCP) fibers," in Structure and Properties of High-Performance Fibers, pp. 113-140, Woodhead Publishing, Cambridge, United Kingdom, 2017.

[32] T. S. Reddy, P. R. S. Reddy, and V. Madhu, "Dynamic behaviour of carbon/ultra high molecular weight polyethylene (UHMWPE) hybrid composite laminates under ballistic impact," Journal of Dynamic Behaviour of Materials, vol. 2020, pp. 1-11, 2020.

[33] G. Bhat, Structure and Properties of High-Performance Fibers, Woodhead Publishing, Cambridge, United Kingdom, 2016.

[34] Y. Liu, C. Zhang, Y. Liu, H. Tan, and C. Wang, "Accelerated ultraviolet aging study of the Vectran fiber," Journal of Applied Polymer Science, vol. 124, no. 4, pp. 3286-3292, 2012.

[35] D. E. Beers and J. E. Ramirez, "Vectran high-performance fibre," The Journal of the Textile Institute, vol. 81, no. 4, pp. 561-574, 1990.

[36] Z. Ophir and Y. Ide, "Injection molding of thermotropic liquid crystal polymers," Polymer Engineering and Science, vol. 23, no. 14, pp. 792-796, 1983.

[37] A. Komorek, R. Szczepaniak, P. Przybylek et al., "Properties of multi-layered polymer composites with Vectran fiber reinforcement," Composite Structures, vol. 256, Article ID 113045 , 2021.

[38] V. P. Shibaev and L. Lam, Liquid Crystalline and Mesomorphic Polymers, Springer Science \& Business Media, Berlin, Germany, 2012.

[39] J. Gao, B. H. Lim, X. Zhai, Y. Nie, N. Kedir, and W. Chen, "Failure behaviors of single high-performance fibers under transverse dynamic cut," International Journal of Impact Engineering, vol. 144, Article ID 103660, 2020.

[40] Z. M. Wan, Y. Y. Liu, and Y. Song, "Research on tensile and tearing properties of Vectran fabric composites," Spacecraft Recovery \& Remote Sensing, vol. 32, 2011.

[41] A. M. Donald, A. H. Windle, and S. Hanna, Liquid Crystalline Polymers (Cambridge Solid State Science), Cambridge University Press, Cambridge, England, 2006.

[42] H. Matsumoto, High-Performance and Specialty Fibers-Concepts, Technology and Modern Applications of Man-Made Fibers for the Future, The Society of Fiber Science and Technology, Tokyo, Japan, 2020. 